\title{
Penentuan Penerima Bantuan Siswa Miskin Menerapkan Metode Multi Objective Optimization on The Basis of Ratio Analysis (MOORA)
}

\author{
Dwika Assrani $^{1}$, Nurul Huda ${ }^{1}$, Rudi Sidabutar ${ }^{1}$, Imam Saputra $^{2}$, Oris Krianto Sulaiman ${ }^{3}$ \\ ${ }^{1}$ Mahasiswa Program Studi Teknik Informatika STMIK Budi Darma, Medan, Indonesia \\ ${ }^{2}$ STMIK Budi Darma, Medan, Indonesia \\ ${ }^{3}$ Program Studi Teknik Informatika, Universitas Islam Sumatera Utara, Medan, Indonesia
}

\begin{abstract}
Abstrak
Program BSM merupakan Program Nasional yang bertujuan untuk menghilangkan halangan siswa miskin berpartisipasi untuk bersekolah dengan membantu siswa miskin memperoleh askses pelayanan pendidikan yang layak, mencegah putus sekolah, menarik siswa miskin untuk kembali bersekolah, membantu siswa memenuhi kebutuhan dalam kegiatan pembelajaran, mendukung program wajib belajar pendidikan 9 Tahun (bahkan hingga tingkat menengah atas), serta membantu kelancaran program sekolah. Untuk mendapatkan dana Bantuan Siswa Miskin (BSM) tersebut, pemerintah menetapkan beberapa kriteria siapa sajakah siswa yang dapat dipenentuankan dan berhak mendapatkan Bantuan Siswa Miskin (BSM) tersebut. Kriteria tersebut nantinya yang akan membantu pihak sekolah atau instansi pendidikan dalam menetukan siswa mana yang dapat dipenentuankan untuk menerima Dana Bantuan Siswa Miskin. Maka dari itu sebuah instansi penndidikan harus memiliki Sistem Pendukung Keputusan perekomenasian Dana Siswa Miskin (BSM) menggunakan metode Multi Objective Optimization on the Basis of Ratio Analysis (MOORA), dengan adanya sistem pendukung keputusan pepenentuanan Bantuan Siswa Miskin (BSM) diharapkan proses pepenentuanan berjalan baik, tepat sasaran, dan diterima oleh orang yang berhak. Dengan demikian pengambil keputusan dapat membandingkan kinerja antara sistem yang lama dengan sistem pendukung keputusan penentuan dana BSM dengan metode Multi Objective Optimization On The Basis Of Ratio Analysis (MOORA) tanpa harus meminta kembali data-data siswa yang akan diberi dana Bantuan Siswa Miskin.
\end{abstract}

Kata kunci: Sistem Pendukung Keputusan, Dana BSM, Multi Objective Optimization On The Basis Of Ratio Analysis

\begin{abstract}
The BSM Program is a National Program aimed at eliminating the barriers of poor students participating to school by helping poor students obtain proper access to education services, preventing dropping out, attracting poor students to return to school, helping students meet needs in learning activities, supporting compulsory education programs 9 Years (even up to middle level), as well as help smooth school programs. To obtain the Poor Student Assistance (BSM) fund, the government sets out some criteria for who are the students who can be eligible and entitled to receive Poor Student Assistance (BSM). The criteria will be later that will assist the school or educational institution in determining which students can be eligible to receive Poor Student Assistance Fund. Therefore, an educational institution must have a Decision Support Support System of Poor Student Fund (BSM) using Multi-Objective Optimization on the Basis of Ratio Analysis (MOORA) method, with a decision support system of Poor Student Assistance (BSM) is expected to be successful, on target, and accepted by the rightful person. Thus the decision maker can compare the performance between the old system with the BSM funding decision support system with the method of Multi-Objective Optimization On The Basis Of Ratio Analysis (MOORA) without having to ask back the data of students who will be given Poor Student Assistance funds.
\end{abstract}

Keywords: Decision Support System, BSM Fund, Multi-Objective Optimization On The Basis Of Ratio Analysis

\section{PENDAHULUAN}

Program Bantuan Siswa Miskin merupakan satu dari program nasional, bertujuan membantu siswa kurang mampu untuk bersekolah dan memperoleh pelayanan dari penyelenggaraan pendidikan yang layak. Program BSM juga menarik siswa yang putus sekolah dikarenakan kurangnya dana, untuk dapat melanjutkan sekolah kembali, serta memenuhi kebutuhan dalam kegiatan pembelajaran[1].

Dalam penerapannya Dana BSM digunakan untuk pembelian perlengkapan siswa seperti buku pelajaran, alat tulis, sepatu dan tas, biaya transportasi siswa ke sekolah, uang saku siswa. Dana BSM bisa dibatalkan bila siswa penerima BSM berhenti sekolah[1].

Dalam penerapannya di sekolah, sering dijumpai pihak sekolah yang tidak secara baik dalam memutuskan penerima penerima BSM tersebut kepada siswa miskin. Untuk menghidari keputusan yang salah, maka diterapkan pemakaian komputer dalam membantu pengambil keputusan, yaitu dengan menerapkan sistem pendukung keputusan. Sistem Pendukung Keputusan Sistem pendukung keputusan adalah sistem berbasis komputer yang mampu memecahkan masalah manajemen dalam menghasilkan alternatif terbaik untuk mendukung keputusan yang diambil oleh pengambil keputusan[2]. 
Berdasarkan penelitian terdahulu, Mesran(2017), bahwa menentukan calon siswa baru yang memiliki nilai terbesar dan dapat diterima dalam calon siswa unggul dengan menggunakan metode MOORA, alternatif A1 adalah calon siswa baru yang memiliki nilai terbesar dan dapat diterima[3].

Berdasarkan penelitian terdahulu Muhammad Ashari, Fitri Mintarsih(2017), bahwa pemilihan bibit ikan tawar dengan menggunakan metode MOORA, Ikan Lele sebagai alternatif terbaik bibit ikan air tawar dengan nilai $-0,1009[4]$. Berdasarkan pendidikan untuk tingkat SMA/SMK sekarang ini semakin mahal, apalagi setiap penggantian kurikulum biaya pendidikan otomatis akan meningkat setiap tahunnya. Sehingga menjadikan masyarakat miskin merasa sulit berpartisipasi menyekolahkan anaknya sampai mengenyam pendidikan sampai menengah atas. Salah satu alas an rendahnya partisipasi pendidikan khususnya pada kelompok miskin adalah tingginya biaya pendidikan baik biaya langsung maupun tidak langsung. Biaya langsung meliputi antara lain iuran sekolah, buku, seragam, dan alat tulis, sementara biaya tidak langsung antara lain transportasi, kursus, uang saku dan biaya lain-lain. Program Bantuan Siswa Miskin(BSM) merupakan Program Nasional yang bertujuan menghilangkan halangan siswa miskin berpartisipasi untuk bersekolah dengan membantu siswa miskin memperoleh akses pelayanan pendidikan yang layak, mencegah putus sekolah, menarik siswa miskin untuk kembali bersekolah, membantu siswa memenuhi kebutuhan dalam kegiatan pembelajaran, mendukung program Wajib Belajar Pendidikan Dasar Sembilan Tahun (bahkan hingga tingkat menengah atas), serta membantu kelancaran program sekolah.

\section{TEORITIS}

\subsection{Bantuan Siswa Miskin (BSM)}

Bantuan Siswa Miskin (BSM) merupakan kebijakan pembangunan pendidikan yang bertujuan untuk memperluas akses pendidikan dasar dan menengah yang bermutu bagi siswa dari keluarga tidak mampu/miskin. Keberhasilan program pemberian bantuan ini diharapkan mampu menaikkan pencapaian Angka Partisipasi Kasar (APK) dan Angka Partisipasi Murni (APM) yang menjadi indikator keberhasilan program wajib belajar pendidikan dua belas tahun[1].

\subsection{Multi Objective Optimization On The Basis Of Ratio Analysis (MOORA)}

Metode MOORA adalah metode yang diperkenalkan oleh Braurers dan Zavadkas (2006). Metode yang relatif baru ini digunakan oleh Braurers (2003) dalam suatu pengambilan keputusan multi kriteria. Metode MOORA memiliki tingkat fleksibilitas dan kemudahan untuk dipahami dalam memisahkan subjektif dari suatu proses evaluasi ke dalam kriteria bobot keputusan dengan beberapa atribut pengambilan keputusan[4].

1. Buat sebuah matriks keputusan

$x=\left[\begin{array}{cccc}x_{11} & x_{12} & \cdot & x_{1 n} \\ x_{21} & x_{11} & \cdot & x_{2 n} \\ \cdot & \cdot & \cdot & \cdot \\ x_{m 1} & x_{m 1} & \cdot & x_{m n}\end{array}\right]$.

2. Melakukan normalisasi terhadap matrik $\mathrm{x}$

$x_{i j}^{*}=x_{i j} / \sqrt{\left[\sum_{i=1}^{m} x_{i j}^{2}\right](j=1,2, \ldots, n)} \ldots$

3. Mengoptimalkan Atribut

$y_{i}=\sum_{j=1}^{g} x_{i j}^{*}-\sum_{j=g+1}^{n} x_{i j}^{*}$

Apabila menyertakan bobot dalam pencarian yang ternormalisasi maka rumusnya

$y_{i}=\sum_{j=1}^{g} w_{j} x_{i j}^{*}-\sum_{j=g+1}^{n} w_{j} x_{i j}^{*}(j=1,2, \ldots, n)$.

\section{ANALISA DAN PEMBAHASAN}

Berdasarkan banyaknya siswa yang akan direkomendasikan dana BSM diambil dari 5 orang siswa sebagai contoh penerapan metode Multi Objective Optimization On The Basis Of Ratio Analysis (MOORA) dalam menentukan penerimaan dana BSM. Pada tabel 1 dan 2 merupakan kriteria dan alternatif. 
Tabel 1. Kriteria

\begin{tabular}{|c|l|c|c|}
\hline Kriteria & \multicolumn{1}{|c|}{ Keterangan } & Bobot & Jenis \\
\hline $\mathrm{C}_{1}$ & Penghasilan Orang Tua & $40 \%$ & Cost \\
\hline $\mathrm{C}_{2}$ & Tanggungan & $25 \%$ & Benefit \\
\hline $\mathrm{C}_{3}$ & Absensi Kehadiran & $20 \%$ & Benefit \\
\hline $\mathrm{C}_{4}$ & Nilai Rata-rata Rapor & $15 \%$ & Benefit \\
\hline
\end{tabular}

Tabel 2. Alternatif

\begin{tabular}{|c|c|c|c|c|}
\hline Alternatif & $\mathbf{C}_{\mathbf{1}}$ & $\mathbf{C}_{\mathbf{2}}$ & $\mathbf{C}_{\mathbf{3}}$ & $\mathbf{C}_{\mathbf{4}}$ \\
\hline $\mathrm{A}_{1}$ & 2.500 .000 & 3 & 70 & 70 \\
\hline $\mathrm{A}_{2}$ & 1.200 .000 & 5 & 80 & 75 \\
\hline $\mathrm{A}_{3}$ & 1.000 .000 & 6 & 100 & 90 \\
\hline $\mathrm{A}_{4}$ & 2.000 .000 & 4 & 60 & 65 \\
\hline $\mathrm{A}_{5}$ & 1.500 .000 & 5 & 60 & 80 \\
\hline
\end{tabular}

Langkah-langkah penggunaan metode MOORA:

1. Membuat matriks keputusan

$$
X=\left[\begin{array}{cccc}
2.500 .000 & 3 & 70 & 70 \\
1.200 .000 & 5 & 80 & 75 \\
1.000 .000 & 6 & 100 & 90 \\
2.000 .000 & 4 & 60 & 65 \\
1.500 .000 & 5 & 60 & 80
\end{array}\right]
$$

2. Berdasarkan persamaan $\mathrm{k} 2$, melakukan normalisasi matriks $\mathrm{X}$

$$
\begin{aligned}
C_{1} & =\sqrt{\begin{array}{l}
2.500 .000^{2}+1.200 .000^{2}+1.000 .000^{2}+ \\
2.000 .000^{2}+1.500 .000^{2}
\end{array}} \\
& =\sqrt{14.940 .000 .000 .000}=3.865 .229,618018
\end{aligned}
$$

$A_{11}=2.500 .000 / 38,652=0,6467$

$A_{21}=1.200 .000 / 38,652=0,3104$

$A_{31}=1.000 .000 / 38,652=0,2587$

$A_{41}=2.000 .000 / 38,652=0,5174$

$A_{51}=1.500 .000 / 38,652=0,3880$

$C_{2}=\sqrt{3^{2}+5^{2}+6^{2}+4^{2}+5^{2}}=\sqrt{111}$

$$
=10.535
$$

$A_{11}=3 / 10.535=0,2847$

$A_{21}=5 / 10.535=0,4746$

$A_{31}=6 / 10.535=0,5923$

$A_{41}=4 / 10.535=0,3796$

$A_{51}=5 / 10.535=0,4746$

$C_{3}=\sqrt{70^{2}+80^{2}+100^{2}+60^{2}+60^{2}}=\sqrt{28500}$

$$
=168,8194
$$

$A_{11}=70 / 168,8194=0,4146$

$A_{21}=80 / 168,8194=0,4738$

$A_{31}=100 / 168,8194=0,5923$

$A_{41}=60 / 168,8194=0,3554$

$A_{51}=60 / 168,8194=0,3554$

$C_{4}=\sqrt{70^{2}+75^{2}+90^{2}+65^{2}+80^{\cdot 2}}=\sqrt{29250}$

$$
=171.0263
$$

$A_{11}=70 / 171.0263=0,4092$ 
$A_{21}=75 / 171.0263=0,4385$

$A_{31}=90 / 171.0263=0,5262$

$A_{41}=65 / 171.0263=0,3800$

$A_{51}=80 / 171.0263=0,4677$

Hasil dari Normalisasi matriks $\mathrm{X}$ diperoleh matrik $X_{I J}^{*}$

$X_{I J}^{*}=\left[\begin{array}{llll}0,6467 & 0,2847 & 0,4146 & 0,4092 \\ 0,3104 & 0,4746 & 0,4738 & 0,4385 \\ 0,2587 & 0,5923 & 0,5923 & 0.5262 \\ 0,5174 & 0,3796 & 0,3554 & 0,3800 \\ 0,3880 & 0,4746 & 0,3554 & 0,4677\end{array}\right]$

3. Mengoptimalkan atribut Menyertakan bobot dalam pencarian yang ternormalisasi

$\left[\begin{array}{llll}0,6467(0,4) & 0,2847(0,25) & 0,4146(0,2) & 0,4092(0,15) \\ 0,3104(0,4) & 0,4746(0,25) & 0,4738(0,2) & 0,4385(0,15) \\ 0,2587(0,4) & 0,5923(0,25) & 0,5923(0,2) & 0.5262(0,15) \\ 0,5174(0,4) & 0,3796(0,25) & 0,3554(0,2) & 0,3800(0,15) \\ 0,3880(0,4) & 0,4746(0,25) & 0,3554(0,2) & 0,4677(0,15)\end{array}\right] x W j$

Hasil perkaliian dari penyetaraan bobot

$\left[\begin{array}{llll}0,2586 & 0,0711 & 0,0829 & 0,0613 \\ 0,1241 & 0,1186 & 0,0947 & 0,0657 \\ 0,1034 & 0,1423 & 0,1186 & 0.0789 \\ 0,2069 & 0,0949 & 0,0710 & 0,0570 \\ 0,1552 & 0,1186 & 0,0710 & 0,0701\end{array}\right]$

Tabel 3. Daftar Yi

\begin{tabular}{|c|c|c|c|}
\hline Alternatif & Maximum $\mathbf{C}_{\mathbf{2}}+\mathbf{C}_{\mathbf{3}}+\mathbf{C}_{4}$ & Minumum $\mathbf{C}_{\mathbf{1}}$ & Y (Max-Min) \\
\hline $\mathrm{A}_{1}$ & 0,2153 & 0,2586 & $-0,0433$ \\
\hline $\mathrm{A}_{2}$ & 0,2790 & 0,1241 & 0,1549 \\
\hline $\mathrm{A}_{3}$ & 0,3398 & 0,1034 & 0,2364 \\
\hline $\mathrm{A}_{4}$ & 0.2229 & 0,2096 & 0,0133 \\
\hline $\mathrm{A}_{5}$ & 0,2597 & 0,1552 & 0,1045 \\
\hline
\end{tabular}

Tabel 4. Hasil Rangking

\begin{tabular}{|c|c|c|}
\hline Alternatif & Hasiil & Peringkat \\
\hline $\mathrm{A}_{3}$ & 0,2364 & 1 \\
\hline $\mathrm{A}_{2}$ & 0,1549 & 2 \\
\hline $\mathrm{A}_{5}$ & 0,1045 & 3 \\
\hline $\mathrm{A}_{4}$ & 0,0133 & 4 \\
\hline $\mathrm{A}_{1}$ & $-0,0433$ & 5 \\
\hline
\end{tabular}

\section{KESIMPULAN}

Berdasarkan hasil penelitian yang dilakukan, diambil beberapa kesimpulan, yaitu:

1. Sistem penentuan dana BSM membantu pengambilan keputusan dalam masalah siswa yang akan ditentukan mendapatkan dana BSM secara cepat dan mudah.

2. Hasil penentuan dana BSM untuk siswa miskin menjadi lebih objektif karena pengambil keputusan tidak secara langsung menentukan dan menilai siswa yang akan ditentukan.

3. Penentuan bobot dari kriteria yang digunakan sangat mempengaruhi hasil perhitungan dari MOORA

\section{REFERENCES}

[1] D. P. Madrasah, D. Jenderal, P. Islam, and K. A. Ri, Petunjuk Teknis Bantuan Siswa Miskin Tahun 2014. Jakarta, 2014.

[2] T.-P. Turban, E., Aronson, J., \& Liang, Decision Support Systems And Inteligence System. US: Prentice-Hall, 2005. 
[3] Mesran, R. K. Hondro, M. Syahrizal, A. P. U. Siahaan, R. Rahim, and Suginam, “Student Admission Assessment using Multi-Objective Optimization on the Basis of Ratio Analysis (MOORA)," J. Online Jar. COT POLIPT, vol. 10, no. 7, pp. 1-6, 2017.

[4] M. Ashari and F. Mintarsih, "Aplikasi Pemilihan Bibit Budidaya Ikan Air Tawar dengan Metode MOORA - Entropy," vol. 5341, no. October, 2017.

[5] D. Handoko, M. Mesran, S. D. Nasution, Y. Yuhandri, and H. Nurdiyanto, “Application Of Weight Sum Model (WSM) In Determining Special Allocation Funds Recipients,” IJICS (International J. Informatics Comput. Sci., vol. 1, no. 2, pp. 31-35, 2017.

[6] M. Sumitre and R. Kurniawan, "Rancang Bangun Sistem Pendukung Keputusan Seleksi Penerimaan Tenaga Pengajar Dengan Metode Fuzzy Inference System (FIS) Mamdani,” J. Inform., vol. 14, no. 1, pp. 61-71, 2014.

[7] H. Nurdiyanto and Heryanita Meilia, "SISTEM PENDUKUNG KEPUTUSAN PENENTUAN PRIORITAS PENGEMBANGAN INDUSTRI KECIL DAN MENENGAH DI LAMPUNG TENGAH MENGGUNAKAN ANALITICAL HIERARCHY PROCESS (AHP)," in Seminar Nasional Teknologi Informasi dan Multimedia 2016, 2016, no. February, pp. 1-7.

[8] J. Simarmata, Rekayasa Perangkat Lunak. Yogyakarta: Andi, 2010.

[9] J. Simarmata, Pengenalan Teknologi Komputer dan Informasi. Yogyakarta: Andi, 2006.

[10] M. I. Setiawan et al., "Business Centre Development Model of Airport Area in Supporting Airport Sustainability in Indonesia," J. Phys. Conf. Ser., vol. 954, no. 1, p. 12024, 2018.

[11] N. W. Al-Hafiz, Mesran, and Suginam, "Sistem Pendukung Keputusan Penentukan Kredit Pemilikan Rumah Menerapkan MultiObjective Optimization on the Basis of Ratio Analysis ( Moora )," KOMIK (Konferensi Nas. Teknol. Inf. dan Komputer), vol. I, no. 1, pp. 306-309, 2017.

[12] G. Ginting, Fadlina, Mesran, A. P. U. Siahaan, and R. Rahim, “Technical Approach of TOPSIS in Decision Making,” Int. J. Recent Trends Eng. Res., vol. 3, no. 8, pp. 58-64, 2017.

[13] T. Murti, L. A. Abdillah, and M. Sobri, "Sistem Penunjang Keputusan Kelayakan Pemberian Pinjaman Dengan Metode Fuzzy Tsukamoto," Semin. Nas. Inov. dan Tren (SNIT)2015, pp. 252-256, 2015.

[14] P. Karande and S. Chakraborty, "Application of multi-objective optimization on the basis of ratio analysis (MOORA) method for materials selection," Mater. Des., vol. 37, no. 2, pp. 317-324, 2012.

[15] Onur Önay and B. F. Yıldırım, "Evaluation of NUTS Level 2 Regions of Turkey by TOPSIS , MOORA and VIKOR 1,” Int. J. Humanit. Soc. Sci., vol. 6, no. 1, pp. 212-221, 2016.

[16] P. Karande, E. K. Zavadskas, and S. Chakraborty, "A study on the ranking performance of some MCDM methods for industrial robot selection problems," Int. J. Ind. Eng. Comput., vol. 7, no. 3, pp. 399-422, 2016.

[17] A. J. Putra, L. A. Abdillah, and H. Yudiastuti, "Penentuan sekolah dasar negeri terbaik kota Palembang dengan metode weighted sum model (WSM) dan weighted product model (WPM) menggunakan visual basic.net 2015," Sentikom, no. September, pp. 1-6, 2016. 